\title{
Modelling for water supply of irrigated cropping systems on climate change
}

\author{
Pasquale Campi, Alejandra Navarro, Luisa Giglio, Angelo D. Palumbo, Marcello Mastrorilli \\ Consiglio per la Ricerca e la sperimentazione in Agricoltura - Unità di ricerca per i Sistemi \\ Colturali degli Ambienti caldo-aridi (CRA-SCA), Bari, Italy
}

\begin{abstract}
The vulnerability of Mediterranean environment due to climatic changes makes necessary to define the effects of the increase of $\mathrm{CO}_{2}$ atmospheric concentration and the consequent alterations of temperature and precipitation variations upon the processes which regulate the plants water supply. The traditional research can not meet the needs of this information because of the difficulty of carrying out the experiments. Therefore, it is necessary to use models based upon mathematical representation of the processes and interactions between climatic scenarios, plant and soil, with which to simulate different agronomic situations. The integration of global circulation models with water balance models is a valid tool for studying the influence of climatic changes on water supply. This study took into account the influence of climatic changes on water supply of poly-annual (artichoke and asparagus) and annual (potato and broccoli) crops with the CRITERIA simulation model of water balance. The simulations were performed with two future climate scenarios (A2 and $\mathrm{B} 1$ ). The results of the simulations highlight how the A2 scenario gives a greater influence on cycle length of crops which develop in summer time determining a reduction of crop cycle from $15-20 \%$ compared to the observed data, and so, as a consequence in the future, the crops with a summer crop cycle will be subjected to reductions of water supply up to $25 \%$.
\end{abstract}

Correspondence: Dr. Pasquale Campi, Consiglio per la Ricerca e la sperimentazione in Agricoltura - Unità di ricerca per i Sistemi Colturali degli Ambienti caldo-aridi (CRA-SCA), via Celso Ulpiani 5, 70125 Bari, Italy.

Tel. +39.080 .5475014 - Fax: +39.080 .5475023 .

E-mail: pasquale.campi@entecra.it

Key words: artichoke, asparagus, potato broccoli, CRITERIA model, evapotranspiration, water balance.

Acknowledgements: this research was funded by CLIMESCO Evolution of cropping systems as affected by climate change project, contract n. 285, 20/02/2006 (Ministry for Education, University and Research).

Received for publication: 18 April 2011.

Accepted for publication: 24 January 2012.

(C) Copyright P. Campi et al., 2012

Licensee PAGEPress, Italy

Italian Journal of Agronomy 2012; 7:e14

doi:10.4081/ija.2012.e14

This article is distributed under the terms of the Creative Commons Attribution Noncommercial License (by-nc 3.0) which permits any noncommercial use, distribution, and reproduction in any medium, provided the original author(s) and source are credited.

\section{Introduction}

The results of the international scientific research in the climatology field are showing more convincing proves that we are going through a period of global climatic change.

The Earth's climate is adapting to the increase of greenhouse gas emission levels occurring in the last 150 years, commonly known as the major reason of variation together with the overlapping to natural climatic changes. In the last decades, observations of trends in temperature confirmed the tendency towards change expected by mathematical models, and not all attributable to natural variation. In the production sectors, agriculture represents beyond doubt one of those most sensitive to the current changes being strongly dependent on climate and meteorological trends (Maracchi et al., 2005). By an evaluation of annual trends of precipitation and water losses (evapotranspiration $\mathrm{ET}_{\text {ref }}$ ) in the Mediterranean environment it can be inferred that it is not possible to ignore irrigation to cultivate species which complete fully or partially their growth cycle during spring and summer time. Moreover, irrigation seasons are longer and longer and also autumn and winter species may require irrigation for obtaining convenient yields (Campi et al., 2005).

In addition, recent studies on the extent of global warming have shown how the increase in temperature is not uniform. In fact, there are areas where the temperature is increased whereas there are others with decreased temperature. In particular, the main international studies achieved can foresee more increased temperatures in the Mediterranean Basin. The tendency of precipitation forecast is rather uncertain: on the whole, the main probabilities indicate a reduction of precipitation in the Mediterranean area (Alcamo et al., 2007). An important decrease in effective rainfall with a sensitive increase in the mean temperature might favourite the process of desertification in southern Italy (Borrelli et al., 2002). The vulnerability in the Mediterranean area to climatic changes makes necessary to define the effects of the alterations of temperatures and precipitation variations on the processes which regulate the crop water requirements to planning crop rotation, irrigation scheduling, etc. The traditional research can not meet completely the need of this information because it is extremely difficult to carry out these experiments. In fact, the traditional experiments are carried out in particular conditions of time and space and thus the results are specific for a well-defined place and season (Lovelli et al., 2010). Therefore, it is necessary to access models based on a mathematical representation of the processes and interactions between climatic scenarios, plant and soil, with which to simulate the various agronomic situations. Although there are many difficulties for the calibration and validation of the models, they can be overcome if it is achieved a high level of confidence with the model that will produce dependable forecasts. Among the different models to simulate this processes, the CRITERIA (Marletto and Zinoni, 1996) model, developed at ARPASIM, simulates crop water supply at a regional scale. CRITERIA, provided by daily data of precipitation and temperature, estimates the evapotranspiration and cal- 
culates the daily flow of superficial runoff, hypodermic runoff and drainage. The water balance takes into account the phenomena of precipitation, irrigation, capillary rise, runoff, evapotranspiration, percolation, redistribution and deep drainage. Some of these variables, such as the precipitation, are easily to be measured; others are estimated through algorithms based on meteorological data and characteristics of soil and crops. The water balance is calculated on a daily basis. In this study CRITERIA model was utilized to predict the influence of climatic changes on water supply of poly-annual (artichoke and asparagus) and annual (summer-spring potato and autumnal broccoli) crops. The model was calibrated and validated with data obtained by a trial carried out on field, and the simulations were related to two future scenarios $\mathrm{A} 2$ and B1 (IPCC, 2007).

\section{Materials and methods}

The trials were carried out in southern Italy on artichoke, asparagus, potato and broccoli crops. In addition, the irrigation treatments were differentiated to obtain agronomic data set to calibrate the CRITERIA model. The research for the artichoke (cv Violetto di Provenza) was carried out on farm in Foggia ( $41^{\circ} 22^{\prime} \mathrm{NL}, 1^{\circ} 35^{\prime} \mathrm{EL}, 80 \mathrm{~m}$ asl) characterized by a semi-arid Mediterranean climate (rainfall $=550 \mathrm{~mm}$, and average temperature $=16^{\circ} \mathrm{C}$ ). The soil was characterized by $45 \%$ clay and $35 \%$ silt and the water contents (measured with Richards chambers) at the field capacity and at the wilting point were 37 and $20 \mathrm{~kg} \mathrm{~kg}^{-1}$, respectively. The artichoke was transplanted in September 2007, while the irrigation treatments started in July 2008 and 2009, by forcing the sleeping crop through abundant irrigations (70 and $30 \mathrm{~mm}$, respectively on $1^{\text {st }}$ July 2008 and on $15^{\text {th }}$ July 2009). The trials for asparagus (cv Grande), broccoli (cv Medway) and potato (cv Arinda) were carried out at the experimental farm of the Agricultural Research Council-Research Unit for Cropping Systems in Dry Environments (CRA-SCA), in Rutigliano (BA) (4059' NL, 1759' EL, 147 $\mathrm{m}$ asl). The location is characterized by a Maritime-Mediterranean climate. The average annual rainfall is $590 \mathrm{~mm}$, concentrated mostly during the autumn, while quite scarce during spring and summer (data recorded from 1980 until 2010 at the Rutigliano agro-meteorological station). The rainfall amount is insufficient to meet the evapotranspiration demand of the atmosphere. The annual $\mathrm{ET}_{\text {ref }}$ is equal to $1150 \mathrm{~mm}$, therefore the annual water deficit is $560 \mathrm{~mm}$ (Campi et al., 2005). The soil was characterized by $40 \%$ clay and $45 \%$ silt and the water contents (measured with Richards chambers) at the field capacity and at the wilting point were 30 and $18 \mathrm{~kg} \mathrm{~kg}^{-1}$, respectively. These textural and hydrological characteristics do not change significantly with the horizontal and vertical dimensions. The soil profile is not deep $(<1 \mathrm{~m})$ and has a moderate total available water (TAW=133 $\mathrm{mm} \mathrm{m}^{-1}$ ). Dates of sowing or transplanting of each crop and the lengths of the crop cycles are reported in Table 1. The irrigation volumes were estimated by the FAO 56 -model and the experimental design, for each crop, was made up of two irrigation regimes: i) 100ET: well-irrigated control restoring $100 \% \mathrm{ET}_{c}$; ii) 50ET: sub-optimal irrigation by reducing irrigation volume by $50 \%$ in comparison with the control treatment. The FAO crop coefficients (Allen et al., 1998) were adopted (Table 2). A strip-plot experimental design was used for each crop, three times replicated. The asparagus and artichoke were irrigated with a micro-flow system (drips) whereas the potato and broccoli were irrigated with an aspersion system (lateral rainger). In order to validate the ET estimated by the CRITERIA model, the daily crop evapotranspiration $\left(\mathrm{ET}_{\mathrm{d}}\right)$ was determined indirectly with the water balance method (Lhomme and Katerji, 1991). The method requires the measurement of the daily variations in soil humidity $(\Delta W)$. These measurements were derived by the values of the dielectric constant which were measured hourly by coaxial probes ( $0.3 \mathrm{~m}$ in length). They were installed, before sowing/transplanting, horizontally into the soil at $0.3 \mathrm{~m}$ in depth. Probes were linked to a TDR100-Campbell data logger CR1000 (Campbell
Scientific, Inc., Logan, UT, USA). These data were used as the input for the Topp equation (Topp and Davis, 1985) which allows for the calculation of the percentage (in volume) of water in the soil. As the Topp equation refers to a generic clay soil, a local calibration was adopted. During a cycle of dehydration of the soil (15 days), the soil humidity values calculated by the Topp equation were correlated to those daily obtained with the reference method (thermo-gravimetric). A linear regression was found for each TDR probe between the humidity values provided by the two methods (Topp equation and thermo-gravimetric). The slope and the intercept of such regressions allowed the local calibration of the TDR-probes.

The daily variation of soil humidity $( \pm \Delta W)$ and rain (R) allowed to come up with the ETd, the only unknown term in the equation:

$$
\mathrm{ET}_{\mathrm{d}}= \pm \Delta \mathrm{W}+\mathrm{R}-\mathrm{D}
$$

The equation for the water balance (1) was simplified to only three terms (Mastrorilli, 1999), since the runoff and capillary rise in the experimental fields (Rutigliano and Foggia) are negligible. In fact, the experimental areas are flat, the soil superficial and sub-soil impedes capillary rise from the deepest layers. Drainage (D) was calculated as equal to the excess of water supply with regards to the capacity of the soil to retain water.

The seasonal water consumption was estimated through the accumulation of ETz-.

The calibration of the CRITERIA model was done taking into account the following inputs measured during the tests:

- Agrometeorological data.

- Leaf Area Index (LAI) trend: it is measured through thermic sums and related values of LAI which are necessary for the initial growth phase (from the transplant to the beginning of growth and from this latter to the maximum development of leaves) and senescence (up to harvesting) to be completed.

Crop coefficient (Kc): It was taken into account and it was obtained by the ratio between ETd, calculated with the Eq. 1 for optimal irrigation's condition (100ET), and $\mathrm{ET}_{0}$, calculated with PenmanMonteith model (Table 3).

Table 1. Month of sowing or transplanting of crops and duration years of trials.

\begin{tabular}{lll} 
Crop & Sowing/transplanting & Years of trials \\
Artichoke & September 2007 & $2008-2009$ \\
Asparagus & May 2006 & $2008-2009$ \\
\hline Broccoli & September & 2008 and 2009 \\
Potato & April & 2009 and 2010 \\
\hline
\end{tabular}

Table 2. The basal FAO crops coefficients $\left(K_{c}\right)$ adopted to calculate crop evapotranspiration.

\begin{tabular}{lccc} 
Crop & $\mathrm{K}_{\mathrm{c}}$ ini & $\mathrm{K}_{\mathrm{c}}$ med & $\mathrm{K}_{\mathrm{c}}$ end \\
Artichoke & 0.15 & 0.95 & 0.90 \\
Asparagus & 0.15 & 0.9 & 0.2 \\
\hline Broccoli & 0.15 & 0.95 & 0.85 \\
Potato & 0.15 & 1.1 & 0.6 \\
\hline
\end{tabular}

Table 3. Crop coefficient $\left(K_{c}\right)$ and fraction depletion $(P)$ values adopted in the irrigation management.

\begin{tabular}{lll} 
Crop & $\mathrm{K}_{c}$ & $\mathrm{P}$ \\
Artichoke & 1.15 & 0.45 \\
Asparagus & 1.05 & 0.45 \\
\hline Broccoli & 0.80 & 0.40 \\
Potato & 1.15 & 0.35 \\
\hline
\end{tabular}


- Root depth: a depth of $0.6 \mathrm{~m}$ was taken into account for all the crops.

- Physical-chemical and hydrological characteristics.

- Irrigation management: an irrigation is scheduled every time the readily water availability is depleted (FC - p TAW), where $\mathrm{p}$ is the threshold value indicated by the FA0 56 (Allen et al., 1998) (Table 3). The sub-optimal regimes are managed by the stress coefficients ( 0 0.99 ) which come from the ratio between the effective and the maximum transpiration. The coefficients of 0.9 and 0.5 were taken into account for the optimal management (100ET) and for the irrigation deficit (50ET), respectively.

For model calibration a data set related to only one year (2009) was used. For simulating water supply in future scenarios, the effect of $\mathrm{CO}_{2}$ on transpiration flow during calibration was not taken into account because the effect, due to the interaction between temperature and $\mathrm{CO}_{2}$, is uncertain (Polley et al., 2002).

In this area of knowledge, for the trials regarding climatic changes it was observed that the increase in $\mathrm{CO}_{2}$ atmospheric concentration results in an increase in stomatal resistance, approximately around $22 \%$ (Ainsworth et al., 2005). As a consequence, there is a reduction of water loss by transpiration. Considering that the transpiration is determined by the vapour pressure gradient between the internal and external part of the leaves, and that this gradient is closely related to the temperature, if this one increases, the transpiration should increase as well. Therefore, a simultaneous action shows up between two effects which drive in opposite directions and can be mutually balanced at leaf's level (Lovelli et al., 2010).

For the model validation the ET was considered, for each crop, year and irrigation treatment. The statistical validation followed the methodology proposed by Loague and Green (1991). Relative Root Mean Square Error (RRMSE) was calculated as follows:

$$
R R M S E=\sqrt{\frac{\sum_{i=1}^{n}\left(P_{i}-O_{i}\right)^{2}}{n}} \cdot \frac{100}{\bar{O}}
$$

where $n$ is the number of observations, $P_{i}$ is the crop evapotranspiration value predicted by CRITERIA ( $\mathrm{ET}_{\text {crit }}$ ), $0 \mathrm{i}$ the observed crop evapotranspiration value $\left(\mathrm{ET}_{\mathrm{s}}\right)$, and $\bar{O}$ the mean of the observed values. RRMSE gives a percentage measurement of the difference between simulated vs observed data. The validation is considered to be excellent when RRMSE is $<10 \%$, good if between $10-20 \%$, acceptable if between 20-30, poor >30 (Jamieson et al., 1991). The RRMSE test provides a value for the model's prediction error rate by placing emphasis on a high level of errors.

Figure 1 indicates the RRSME and the trend obtained from the comparison between the cumulative daily values of crop evapotranspiration estimated through the CRITERIA model and the values observed independently through the water balance for each of the crops and for the two irrigation schedules (100ET and 50ET). In particular, taking into account that the RRMSE test indicates a good level of acceptance of errors from the model (RRMSE varies until 20\%), the CRITERIA model can correctly estimate ET in future scenarios. The simulations were performed with $\mathrm{A} 2$ and $\mathrm{B} 1$, past and future climate scenarios respectively, obtained with statistical downscaling (Pizzigalli et al., 2012).

For every thirty years span $(1980-2005 ; 2010-2039 ; 2040-2069 ; 2070$ 2099) and for every crop and irrigation treatment, a water balance was simulated with the CRITERIA model. Afterwards the figures of the crop variable (cycle lenght) and irrigation (crop evapotransipration, seasonal irrigation volumes, irrigation number and crop coefficients) were analyzed for every thirty-year period, in relation to the past (A2) and future (B1) climatic scenarios.

\section{Results}

\section{Artichoke}

The simulations with future scenarios (Figure 2) show that the crop cycle of the artichoke is reduced by 55 days with the A2 scenario in the 2070-2099 period respect to the present one (1980-2005). The reduction of the crop cycle caused, for the optimal irrigation treatment (100 ET), a decrease of 170 and $133 \mathrm{~mm}$ in the crop evapotranspiration and in the seasonal irrigation volume, respectively. Also values of $K_{c}$ have shown at once a reduction with $\mathrm{A} 2$ scenario going from a mean value of 0.98 in the period from 1980-2005 to 0.91 in the thirty-year period from 2070 to 2099 (Table 4). With a regulated deficit irrigation (50ET), a reduction in the cultural evapotranspiration and in the seasonal irrigation volume occurred of 191 and $153 \mathrm{~mm}$, respectively.

The simulated data show how the reduction in irrigation volumes does not provoke water stress to the artichoke crop since the deficit irrigation caused an ET mean reduction of $10 \%$ in both the past and future scenarios.

\section{Asparagus}

The simulations with future scenarios show that the crop parameters taken into account are changed in both scenarios. In particular, the asparagus crop cycle is reduced in the last thirty years period by 40 days in the A2 scenario and by 30 days in the B2 one (Figure 3). As a consequence, the reduction of crop cycle triggered, a reduction in the $\mathrm{ET}_{\mathrm{c}}$ and seasonal irrigation volume. In addition, the effects induced by the A2 scenario have been more evident on $\mathrm{Kc}$, whose mean values have been reduced from 0.74 to 0.65 (Table 5 ). In the asparagus, as occurred with the artichoke, the reduction in irrigation volume does not produce water stress conditions to the crop, since the deficit irrigation involves an ET mean reduction by $14 \%$ in both past and future scenarios (A2 and B1).

\section{Broccoli}

The simulations for the broccoli crop showed variations only with A2 scenario. Regarding the other crops, an increase of the ETc that result-

Table 4. Simulations of the irrigation variables with past and future scenarios (A2 and B1) on artichoke.

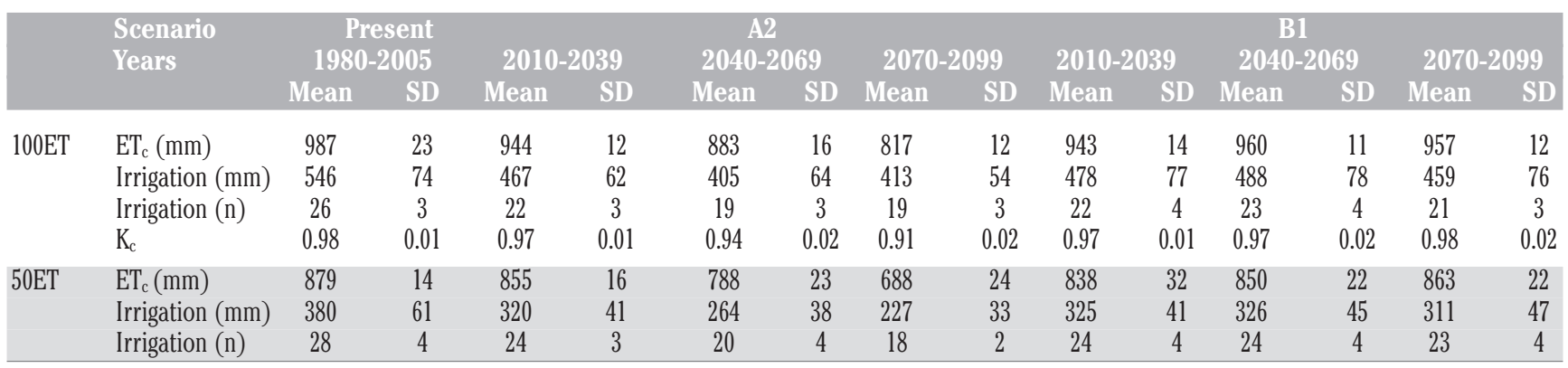


ed from the simulations does not show any variations in the length of the crop cycle. This can be explained through the higher temperatures with the A2 scenario during the autumnal period compared to those of B1. The increase of ET is the main cause of the increase of Kc from 0.65 to 0.70 with $\mathrm{A} 2$ scenario. The regulated water stress did not show any variations of ETc (Table 6).

\section{Potato}

The reduction of potato crop cycle, compared to other crops, is more evident with the B1 scenario (Figure 4). The reduction in irrigation volumes with controlled water stress have showed a mean reduction of ETc by $24 \%$ in both past and future scenarios (A1 and B2) (Table 7). Such a considerable reduction produces a water stress condition to the crop due mainly to a high environmental evapotranspiration demand during the spring-summer period.

\section{Discussion}

The increase in temperatures influences crop life cycles and forest species, and this causes a temporal tendency to anticipate the phenological phases (vegetative stage, flowering and maturation) with more risks for the return of low air temperature, and a different sensitivity to phyto-pathologies, changes in agro-techniques and variations of geographic areas of the species distribution.

The main effect on the crop productivity is depending on the reduced biomass accumulation and, as a consequence, the final yield decreases. Firstly, the results of the simulations here reported highlight how the crop cycle length varies as a function of the season in which the crop grows and as a function of the future scenario. In particular, the A2 scenario mainly influences the cycle length of the crops which develop during summer, whereas the B1 scenario has a greater impact on the crops which develop mainly in spring. In fact, passing from past to future scenario B1 related to the thirty-year period from 2070 to 2099, the crop cycle of artichoke which completes its cycle from summer to spring (in 340 days), and the crop cycle of asparagus which represents mainly a summer development (May - September), are reduced by $20 \%$ and $15 \%$, respectively. On the contrary, compared to A2 scenario, the crop cycle of the potato is mainly reduced with B1 (by $17 \%$ vs. $7 \%$ ), because the analyses of meteorological data highlight higher temperatures in spring time compared to the A2 scenario. In broccoli, slight variations come out since the crop cycle trend is relatively short (90 days) and does not allow to evaluate the effects of the increases in temperature which happen in autumn with the $\mathrm{A} 2$ and $\mathrm{B} 1$ scenarios.

Secondly, taken into account the irrigation variables, the simulations highlight that the crops develop part of their crop cycle in summer, in the future they will be subjected to water supplies which vary with the

Table 5. Simulations of the irrigation variables with past and future scenarios (A2 and B1) on asparagus.

\begin{tabular}{|c|c|c|c|c|c|c|c|c|c|c|c|c|c|c|c|}
\hline & \multirow[t]{2}{*}{$\begin{array}{l}\text { Scenario } \\
\text { Years }\end{array}$} & \multicolumn{2}{|c|}{$\begin{array}{l}\text { Present } \\
\text { 1980-2005 }\end{array}$} & \multicolumn{2}{|c|}{$2010-2039$} & \multicolumn{2}{|c|}{$\begin{array}{c}\mathrm{A} 2 \\
2040-2069\end{array}$} & \multicolumn{2}{|c|}{$2070-2099$} & \multicolumn{2}{|c|}{ 2010-2039 } & \multicolumn{2}{|c|}{$\begin{array}{c}\text { B1 } \\
2040-2069\end{array}$} & \multicolumn{2}{|c|}{$2070-2099$} \\
\hline & & Mean & SD & Mean & SD & Mean & SD & Mean & SD & Mean & SD & Mean & SD & Mean & SD \\
\hline 100ET & $\begin{array}{l}\text { ETc }(\mathrm{mm}) \\
\text { Irrigation }\end{array}$ & 680 & 20 & 652 & 23 & 624 & 25 & 611 & 28 & 662 & 21 & 630 & 23 & 626 & 21 \\
\hline (mm) & $488^{\circ}$ & 32 & 451 & 35 & 445 & 37 & 418 & 29 & 462 & 34 & 443 & 33 & 441 & 32 & \\
\hline & Irrigation (n) & 21 & 1 & 19 & 1 & 18 & 1 & 17 & 1 & 20 & 1 & 19 & 1 & 18 & 1 \\
\hline & $\mathrm{K}_{\mathrm{c}}$ & 0.74 & 0.02 & 0.71 & 0.02 & 0.67 & 0.01 & 0.65 & 0.01 & 0.71 & 0.03 & 0.68 & 0.02 & 0.67 & 0.01 \\
\hline 50ET & $\mathrm{ET}_{\mathrm{c}}(\mathrm{mm})$ & 587 & 26 & 561 & 36 & 515 & 33 & 512 & 38 & 564 & 31 & 521 & 33 & 521 & 24 \\
\hline & Irrigation (mm) & 367 & 24 & 329 & 27 & 315 & 24 & 295 & 20 & 338 & 23 & 316 & 22 & 315 & 22 \\
\hline & Irrigation (n) & 22 & 1 & 19 & 2 & 19 & 2 & 17 & 2 & 20 & 2 & 19 & 2 & 19 & 1 \\
\hline
\end{tabular}

Table 6. Simulations of the irrigation variables with past and future scenarios (A2 and B1) on broccoli.

\begin{tabular}{|c|c|c|c|c|c|c|c|c|c|c|c|c|c|c|c|}
\hline \multirow{2}{*}{\multicolumn{2}{|c|}{$\begin{array}{l}\text { Scenario } \\
\text { Years }\end{array}$}} & \multicolumn{2}{|c|}{$\begin{array}{r}\text { Present } \\
1980-2005\end{array}$} & 2010 & 039 & \multicolumn{2}{|c|}{$\begin{array}{c}\text { A2 } \\
2040-2069\end{array}$} & \multicolumn{2}{|c|}{ 2070-2099 } & \multicolumn{2}{|c|}{ 2010-2039 } & \multicolumn{2}{|c|}{$\begin{array}{c}\text { B1 } \\
2040-2069\end{array}$} & \multicolumn{2}{|c|}{ 2070-2099 } \\
\hline & & Mean & SD & Mean & SD & Mean & SD & Mean & SD & Mean & SD & Mean & SD & Mean & SD \\
\hline $100 \mathrm{ET}$ & $\begin{array}{l}\mathrm{ET}_{\mathrm{c}}(\mathrm{mm}) \\
\text { Irrigation }(\mathrm{mm}) \\
\text { Irrigation }\left(\mathrm{n}^{\circ}\right) \\
\mathrm{K}_{\mathrm{c}}\end{array}$ & $\begin{array}{c}140 \\
18 \\
0.9 \\
0.65\end{array}$ & $\begin{array}{c}12 \\
16 \\
0.8 \\
0.05\end{array}$ & $\begin{array}{c}151 \\
18 \\
0.9 \\
0.69\end{array}$ & $\begin{array}{c}15 \\
13 \\
0.7 \\
0.04\end{array}$ & $\begin{array}{l}153 \\
22 \\
1.1 \\
0.67\end{array}$ & $\begin{array}{c}16 \\
20 \\
1.0 \\
0.04\end{array}$ & $\begin{array}{l}170 \\
35 \\
1.8 \\
0.70\end{array}$ & $\begin{array}{r}17 \\
19 \\
1.0 \\
0.04\end{array}$ & $\begin{array}{c}145 \\
17 \\
0.8 \\
0.64\end{array}$ & $\begin{array}{c}14 \\
12 \\
0.6 \\
0.04\end{array}$ & $\begin{array}{c}142 \\
12 \\
0.6 \\
0.66\end{array}$ & $\begin{array}{c}15 \\
16 \\
0.8 \\
0.02\end{array}$ & $\begin{array}{c}137 \\
12 \\
0.6 \\
0.66\end{array}$ & $\begin{array}{c}13 \\
10 \\
0.5 \\
0.04\end{array}$ \\
\hline $50 \mathrm{ET}$ & $\begin{array}{l}\mathrm{ET}_{\mathrm{c}}(\mathrm{mm}) \\
\text { Irrigation }(\mathrm{mm}) \\
\text { Irrigation }\left(\mathrm{n}^{\circ}\right)\end{array}$ & $\begin{array}{l}137 \\
13 \\
1.3\end{array}$ & $\begin{array}{l}13 \\
11 \\
1.1\end{array}$ & $\begin{array}{l}150 \\
13 \\
1.3\end{array}$ & $\begin{array}{l}14 \\
11 \\
1.1\end{array}$ & $\begin{array}{c}151 \\
18 \\
1.8\end{array}$ & $\begin{array}{l}18 \\
18 \\
1.8\end{array}$ & $\begin{array}{l}165 \\
27 \\
2.7\end{array}$ & $\begin{array}{l}20 \\
16 \\
1.6\end{array}$ & $\begin{array}{l}143 \\
14 \\
1.4\end{array}$ & $\begin{array}{c}14 \\
12 \\
1.2\end{array}$ & $\begin{array}{l}138 \\
10 \\
1.0\end{array}$ & $\begin{array}{l}17 \\
13 \\
1.3\end{array}$ & $\begin{array}{c}136 \\
8 \\
0.8\end{array}$ & $\begin{array}{c}13 \\
8 \\
0.8\end{array}$ \\
\hline
\end{tabular}

Table 7. Simulations of the irrigation variables with past and future scenarios (A2 and B1) on potato

\begin{tabular}{|c|c|c|c|c|c|c|c|c|c|c|c|c|c|c|c|}
\hline & \multirow[t]{2}{*}{$\begin{array}{l}\text { Scenario } \\
\text { Years }\end{array}$} & \multicolumn{2}{|c|}{$\begin{array}{l}\text { Present } \\
1980-2005\end{array}$} & \multicolumn{2}{|c|}{$2010-2039$} & \multicolumn{2}{|c|}{$\begin{array}{c}\mathrm{A} 2 \\
2040-2069\end{array}$} & \multicolumn{2}{|c|}{ 2070-2099 } & \multicolumn{2}{|c|}{$2010-2039$} & \multicolumn{2}{|c|}{$\begin{array}{c}\text { B1 } \\
2040-2069\end{array}$} & \multicolumn{2}{|c|}{$2070-2099$} \\
\hline & & Mean & SD & Mean & SD & Mean & SD & Mean & SD & Mean & SD & Mean & SD & Mean & SD \\
\hline \multirow[t]{4}{*}{$100 \mathrm{ET}$} & $\mathrm{ET}_{\mathrm{c}}(\mathrm{mm})$ & 413 & 9 & 403 & 9 & 407 & 6 & 413 & 10 & 404 & 9 & 394 & 7 & 391 & 14 \\
\hline & Irrigation (mm) & 242 & 47 & 242 & 29 & 258 & 53 & 240 & 28 & 252 & 29 & 250 & 24 & 268 & 32 \\
\hline & Irrigation (n) & 17 & 3 & 17 & 2 & 18 & 3 & 17 & 2 & 17 & 2 & 17 & 2 & 19 & 2 \\
\hline & $\mathrm{K}_{\mathrm{c}}$ & 0.78 & 0.04 & 0.76 & 0.04 & 0.77 & 0.03 & 0.77 & 0.02 & 0.76 & 0.04 & 0.77 & 0.03 & 0.77 & 0.03 \\
\hline \multirow[t]{3}{*}{$50 \mathrm{ET}$} & $\mathrm{ET}_{\mathrm{c}}(\mathrm{mm})$ & 319 & 40 & 303 & 29 & 287 & 40 & 299 & 16 & 293 & 19 & 273 & 13 & 262 & 27 \\
\hline & Irrigation (mm) & 142 & 24 & 137 & 15 & 130 & 20 & 127 & 15 & 135 & 16 & 124 & 15 & 138 & 10 \\
\hline & Irrigation (n) & 14 & 2 & 14 & 1 & 13 & 2 & 12 & 2 & 14 & 3 & 13 & 2 & 14 & 2 \\
\hline
\end{tabular}


a) asparagus


b) artichoke
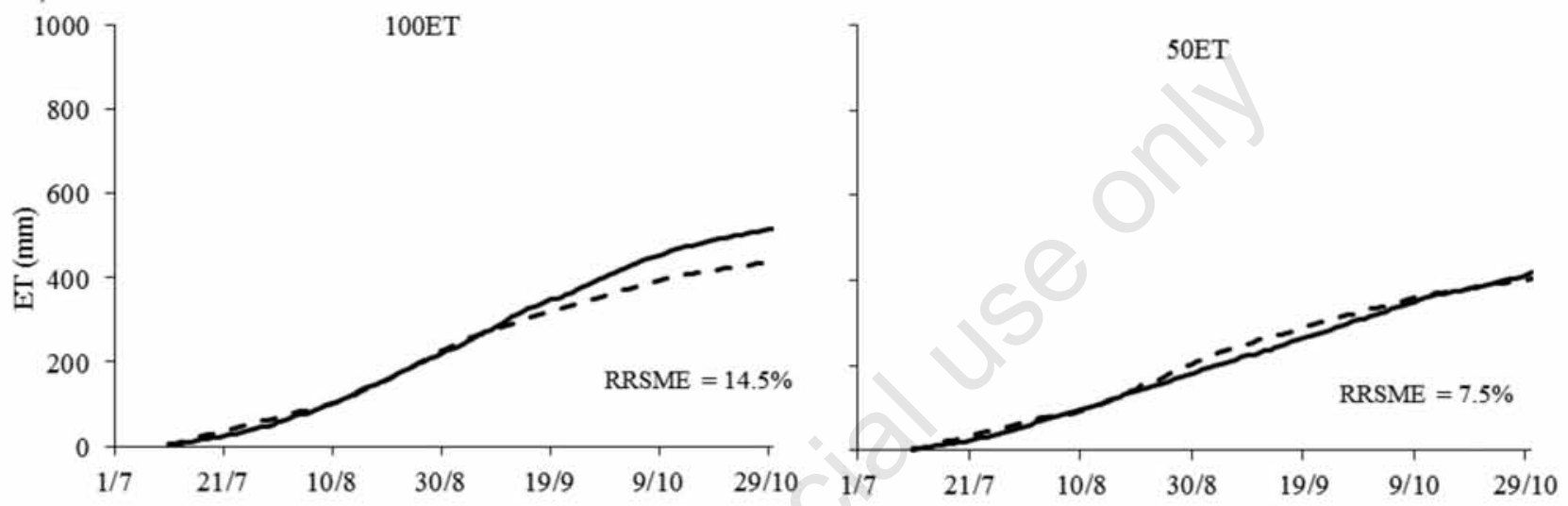

c) potato
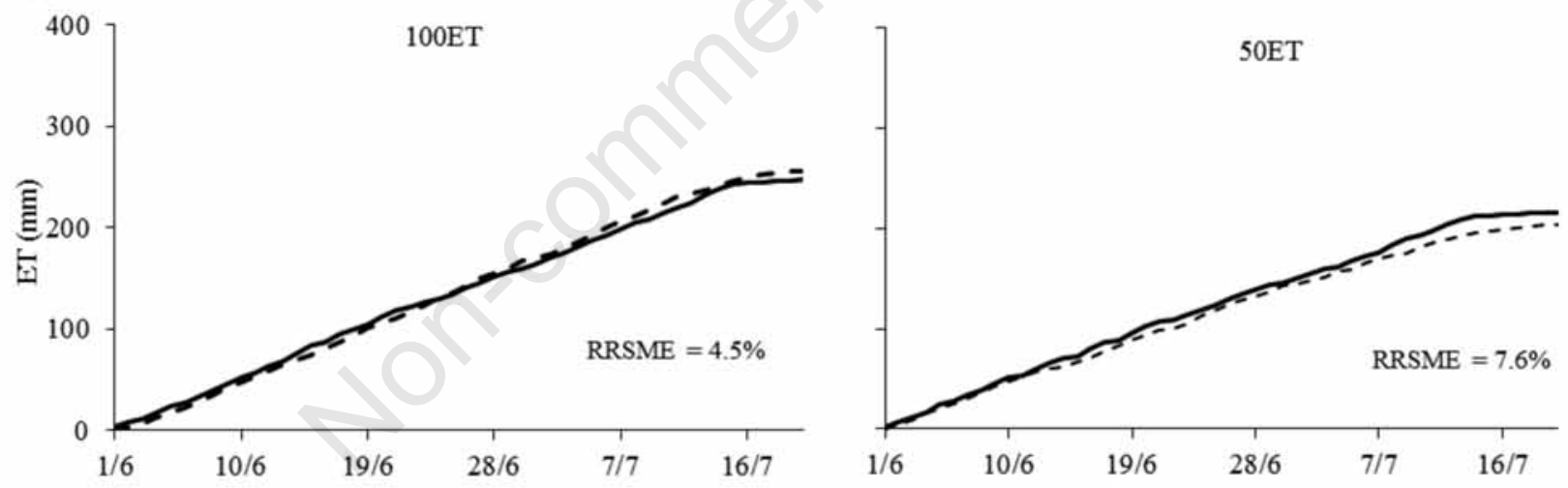

d) broccoli

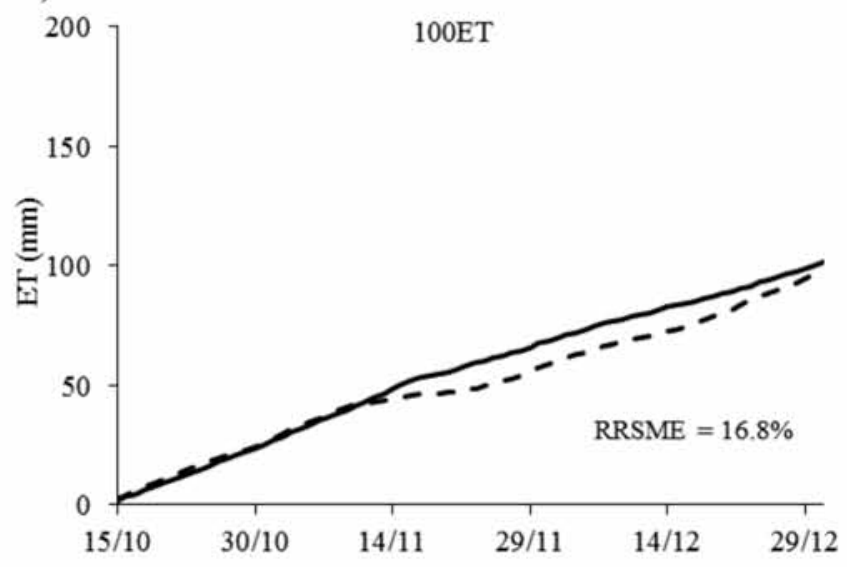

Figure 1. Crop evapotranspiration (sum of ET daily values) estimated according the CRITERIA model and measured through the water balance for three crops (artichoke, asparagus, and potato) in two irrigation regimes (100ET and 50ET), and for broccoli under well watered treatment (100ET). The value (\%) of the Relative Root Mean Square Error (RRMSE) is reported for each treatment. 
type of scenario (A2 or B1). For example, in comparison with the sim-

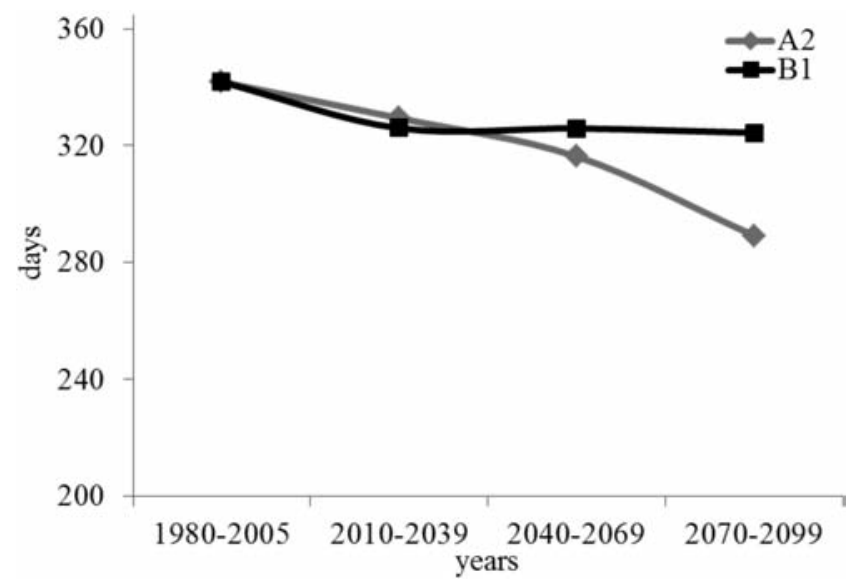

Figure 2. Artichoke: simulated values of the length of the crop cycle (in days) for scenarios A2 and B1.

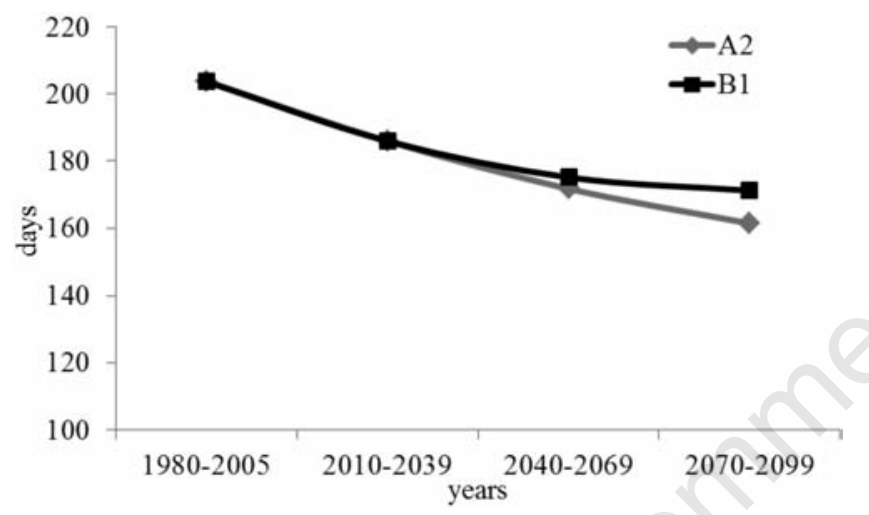

Figure 3. Asparagus: simulated values of the length of the crop cycle (in days) for scenarios A2 and B1.

Figure 4. Potato: simulated values of the length of the crop cycle (in days) for scenarios $\mathrm{A} 2$ and $\mathrm{B} 1$. ulations of the period 1980-2005, in the 2070-2099 the evapotranspiration of the artichoke will be reduced by $18 \%$ for A2 scenario and only by $3 \%$, if it is taken into account B1 scenario. The seasonal irrigation volumes of artichoke reach a reduction of 24 and $15 \%$ in the thirty year period 2070-2099 respect to 1980-2005, according to the A2 and B1 scenario, respectively. In addition, the crops which develop their cycles in a period of the year with more probability of precipitation (spring and autumn) seem to be less subjected to future variations of the climate.

Thirdly, the simulations of A2 and B1 scenarios show how the deficit irrigation does not imply water stress conditions for the crops with summer crop cycle such as asparagus and artichoke, since it determines a reduction of ET lower than 15\%. Instead, more attention needs to be taken into account for the application of the deficit irrigation on the crops which complete their cycles between spring and summer because stress conditions could happen, since a reduction of ET lower than $25 \%$ will occur. The controlled water stress, for annual crop such as broccoli, does not have an important influence because the effects of spare irrigations (1 or 2) are completely masked by the annual precipitations. These estimates provided by CRITERIA are exclusively related to crop water consumptions and not to productivity. Based on these results, in the future there will be less pressure from irrigated farming system on water resources. Nevertheless, it needs to be taken into account that a change in precipitation trend (reduction of rainy days associated to an increase in the intensity of events) could create superficial runoff phenomena and a low accumulation of water in the soil profile or in the ground water tables. As a consequence, there would be soil erosion and in all likelihood an increasing susceptibility to drought, especially in the late spring and summer periods (Imeson and Emmer, 1992; Christensen and Christensen, 2004).

Ultimately, a reduction of rainfalls in autumn-winter period provides less ground waters supply. Moreover, the increase in frequency and intensity of heat waves in the spring-summer period results in a greater occurrence of water stress which can not be restored by irrigation. Finally, a discontinuity of spring rainfalls originates more superficial runoff loss due to more frequent short and heavy storms. All these anomalies create the necessary conditions for an increasing likelihood of the susceptibility to drought and soil erosion.

\section{Conclusions}

This study has given the opportunity to improve the knowledge of future availability and use of water resources, to lay the basis for a sustainable use and for planning future efficiencies of irrigation systems for water conservation. In particular, the CRITERIA model, adaptable to any crop situation,. has been evaluated. Either on regional or farm scale, and with daily calculation, the mathematical simulations have allowed evaluating water supply with which it is possible to estimate the seasonal mean water volumes for different crops and irrigation systems. The modeling is at the bottom of a modern approach to study the relations between climatic changes and agriculture. The study has involved qualitative aspects of water for irrigation use for poly-annual (artichoke and asparagus) and annual (potato and broccoli) crops in anticipation of A2 and B1 future scenarios with CRITERIA model. Regarding the crop cycle length and the irrigation variables, it has been highlighted the ability of the model to define the possible future scenarios. Given the validity of the used approach, the methodology could be extended and adopted to other species. For this kind of applications, the results achieved with the scenarios have shown sensitivity to the difference between $\mathrm{A} 2$ and $\mathrm{B} 1$ scenarios.

It needs to be highlighted that the success of the simulation depends on the quality of data and the crops parameters. Therefore, it should be 
promoted the study of new technical agendas more corresponding to the future agriculture. Furthermore, the nowadays available crops' parameters do not take into account the development of new cultivated varieties with shorter cycle, more resistant to water stress and more efficient to water use. In addition, it is worth keeping in mind that the simulations reported in this study hypothesize the availability of water on demand and with unlimited quantity, even if it is regulated. On the contrary, a reduction of rainy days, which is commonly observed in the Mediterranean area, could cause a situation of water shortage, while an increase in temperatures registered in winter could be the cause of an early development of the phenophases of some cultures.

Therefore, regarding the aspects related to water resource, the agricultural sector could be strongly interested in the variation of the climatic, both for the reduction of soil water availability, the rate of water flows and the reserve of underground water, and for the increase of water supply of cropping species linked with the daily increase of evapotranspiration. Moreover, the increase in temperatures, the reduction in effective rainfalls and the early crop season, compared to normal climatic conditions, call for an early irrigation demand. The occurrence of these phenomena leads not only to an increase of water quantity, which is necessary for an adequate water supply to crops with spring-summer cycle, but also to the need of supplemental irrigations in winter and spring. From a territorial point of view, the irrigated areas, particularly the coastal ones which are supplied by the ground water tables, could be negatively influenced by the effects of climatic changes and also as a consequence of more competition with other sectors which use the same water resource. Ultimately, the internal areas too, included the hilly ones which generally are well supplied, during summer could be in very critical situations.

\section{References}

Ainsworth EA, Long SP, 2005. What have we learned from 15 years of free-air CO2 enrichment (FACE) Ameta-analytic review of the responses of photosynthesis, canopy properties and plant production to rising C02. New Phytol. 165:351-372.

Alcamo J, Florke M, Marker M, 2007. Future long-term changes in global water resources driven by socio-economic and climatic changes. Hydrol. Sci. J. 52:247-275.

Allen RG, Pereira LS, Raes D, Smith M, 1998. Crop evapotranspiration. Guidelines for computing crop water requirements. FAO Irrigation and Drainage Paper No. 56. FA0 Publ., Roma, Italy.

Borrelli G, Giordano L, Iannetta M, Sciortino M, 2002. Report from Italy: the identification of sensitive areas in Italy. The MEDRAP concerted action to support the northern Mediterranean action programme to combat desertification. pp 243-249 in Proc. 2nd Workshop on Identification of Sensitive Areas in the northern Mediterranean, Tróia, Portugal.
Campi P, Colucci R, Mastrorilli M, 2005. Andamenti meteorologici stagionali e gestione irrigua. In: M.M. Giuliani and G. Gatta (eds.) Ricerca ed innovazione per le produzioni vegetali e la gestione delle risorse agro-ambientali. pp 113-114 in Atti $36^{\circ}$ Convegno SIA, Foggia, Italia.

Christensen OB, Christensen JH, 2004. Intensification of extreme European summer precipitation in a warmer climate. Global Planet. Change 44:107-117.

Imeson IM, Emmer AC, 1992. Implications of climatic change on land degradation in the Mediterranean. In: L. Jeftic, J.D. Milliman and G. Sestini (eds.) Climatic Change and the Mediterranean. Arnold Ed., London, UK, pp 95-128.

Intergovernmental Panel on Climate Change, 2007. Summary for policymakers. In: S. Solomon, D. Qin, M. Manning, Z. Chen, M. Marquis, K.B. Averyt, M. Tignor and H.L. Miller (eds.) Climate Change 2007: The Physical Science Basis. Contribution of Working Group I to the 4th Assessment Report of the Intergovernmental Panel on Climate Change. Cambridge University Press, New York, NY, USA.

Lhomme JP, Katerji N, 1991. A simple modelling of crop water balance for agrometeorological application. Ecol. Model. 57:11-25.

Loague KM, Green RE, 1991. Statistical and graphical methods for evaluating solute transport models: overview and application. J. Contam. Hydrol. 7:51-73.

Lovelli S, Perniola M, Di Tommaso T, Ventrella D, Moriondo M, Amato M. 2010. Effects of rising atmospheric CO2 on crop evapo-transpiration in a Mediterranean area. Agr. Water Manage. 97:1287-1292.

Mastrorilli M, 1999. Sviluppo di modelli idrologici per ambienti mediterranei. Bollettino SISS 48:245-250.

Maracchi G, Genesio L, Magno R, Ferrari R, Crisci A, Bottai L, 2005. Progetto DesertNet - Programma Interreg III B - MEDOCC - Asse 4 Misura 4, WP A10 - Azione pilota in Toscana "I diagrammi del clima in Toscana" LAMMA-CRES in collaborazione con il LAMMA, coordinati dal CNR-IBIMET.

Marletto V, Zinoni F, 1996. The CRITERIA project: integration of satellite, radar, and traditional agroclimatic data in a GIS-supported water balance modelling environment. In: N.R. Dalezios (ed.) EUR 18328, pp 173-178 in Proc. COST 77, 79, 711 Int. Symp. on Applied Agrometeorology and Agroclimatology, Volos, Greece.

Pizzigalli C, Palatella L, Zampieri M, Lionello P, Miglietta MM, Paradisi $\mathrm{P}, 2012$. Dynamical and statistical downscaling of precipitation and temperature in a Mediterranean area. Ital. J. Agron. 7:e2.

Polley HW, 2002. Implications of atmospheric and climatic change for crop yield and water use efficiency. Crop Sci. 42:131-140.

Topp GC, Davis JL, 1985. Time domain reflectometry (TDR) and its application to irrigation scheduling. In: D. Hillel (ed.) Advances in Irrigation, Vol. 3. Accademic Press, New York, NY, USA, pp 107-127. 